\title{
Genetic Algorithm based Approach for Reduction of Total Harmonic Distortion in Photo Voltaic Inverter
}

\author{
Geetika Gera \\ Student in M.Tech, Department of \\ Computer Science Engineering, \\ Kautilya Institute of Technology \\ and Engineering, Jaipur
}

\author{
Ram Kishan Bairwa \\ Assistant professor, Department \\ of Computer Science Engg., \\ Kautilya Institute of Technology \\ and Engineering, Jaipur
}

\author{
Darshan Kumar \\ Assistant professor, Department \\ of Electronics and Comunication \\ Engineering,JECRC UDMI \\ College of Engineering, Jaipur
}

\begin{abstract}
In this paper, a genetic algorithm (GA) optimization technique is applied to cascaded multilevel photo voltaic inverter to remove pre specified order of harmonics and to reduce THD. Genetic Algorithm is developed as the preferred solution algorithm of specific harmonic elimination (PWM-SHE) switching pattern. This paper describes an efficient genetic algorithm that reduces significantly the computational burden resulting in fast convergence. An 11-level and 7-level inverter is preferred as a case study, and optimum switching angles are determined to eliminate low order harmonics and to reduce THD. Comparison has been done between the 7-level and 11-level with respect to the consideration of THD. Simulation results validate purpose method.
\end{abstract}

\section{Keywords}

Genetic algorithm, photo voltaic inverter, Selective harmonic elimination pulse width modulation (SHEPWM), Total harmonic distortion

\section{INTRODUCTION}

In recent years, multilevel inverters have been paying attention on and preferred as high power and high voltage ones. These multilevel inverters can increase the power by $(n-1)$ times than that of two-level inverter through the series connection of power semiconductor devices. Use of multilevel inverters is becoming popular for high power applications [1]-[5], especially in the distributed generation where a number of batteries, fuel cells, solar cell, and micro-turbines can be connected through a multilevel inverter to feed a load or the ac grid without voltage balancing problems. Another major advantage of multilevel inverters is that their switching frequency is lower than a traditional two-level inverter, which leads to reduced switching losses [1], [3], [6]. The topologies for high photo voltaic inverters are classified into three types [2], [6]-[11]: the diode clamped inverter, the flying capacitor inverter and the cascaded inverter. Among these inverters, the cascaded inverter has the advantages that the DC-link voltage is balanced, circuit layout flexibility, and it has the least components per phase but require many separated dc sources in motor drive applications. The cascaded inverter has been largely studied and used in fields of SVCs (static VAR compensators), stabilizers, HVDC transmissions and so on [12]-[16]. Many switching strategies are applied to multilevel inverter to reduce harmonics, but SHEPWM is most well-known strategy. SHE-based methods have been proposed for both two-level [17]-[19] and multilevel inverters. This paper is focusing on the SHE-based methods for multilevel inverters. The general function of this multilevel inverter is to synthesize a staircase waveform from several separate dc sources (SDCSs), which may be obtained from solar cells, fuel cells, batteries, ultra capacitors, etc. For output staircase waveform, it is necessary to obtain the switching timing angles or the conducting angles of switching devices. The conventional method has the merit that the predominant loworder harmonics can be eliminated. However, it has to solve simultaneous equations, which are the set of nonlinear transcendental equations for the fundamental component and the harmonic ones. It is difficult to obtain the conducting angles because the conventional method needs an iterative method such as the Newton-Raphson one. Additionally, the switching angles are obtained by means of an off-line calculation to minimize the harmonics for each modulation index, which leads to increased use of look-up tables. Therefore, Genetic Algorithm (GA) [20] [23] is adopted here to replace numerical algorithms to overcome this difficulty, because of its intrinsic ability to begin searching randomly, handle large amount data simultaneously and "jump" out of local optimum automatically. GA is kind of artificial intelligence approaches, and origins from optimizing problems. It has entirely different operation mechanism, comparing with numerical methods based on mathematical differential operation, which needs on some extent restrict requirements on objectives.

\subsection{Structure of cascaded multi level inverter}

The cascaded multilevel inverter is one of several multilevel configurations. It is formed by connecting several single-phase $\mathrm{H}$-bridge inverters in series as shown in Fig. 1 for 11-level inverter Each H-bridge has its own isolated DC source. Each separated DC sources is connected to H-bridge inverter and can produce voltages of $0,+\mathrm{Vdc}$ and $-\mathrm{Vdc}$, by different combination of the four switches, S1, S2, S3 and S4, where Vdc is the voltage of its DC bus. 


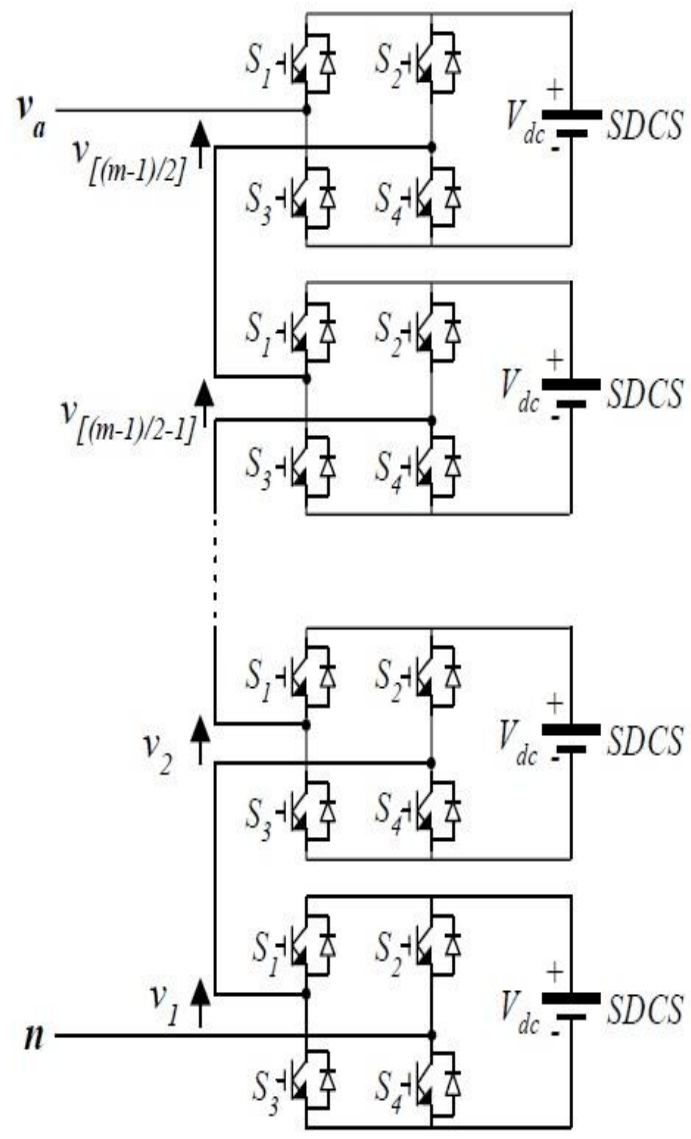

Fig. 1 Structure of cascaded multilevel Inverter

Each inverter generates quasi-square wave voltage waveform with different duty cycle ratios, which together form the staircase output voltage waveform as shown in Fig. 2The synthesized voltage waveform is, therefore, the sum of the inverter outputs. The number of output phase voltage levels in a cascade multilevel inverter is then $2 s+1$, where $s$ is the number of isolated dc sources.

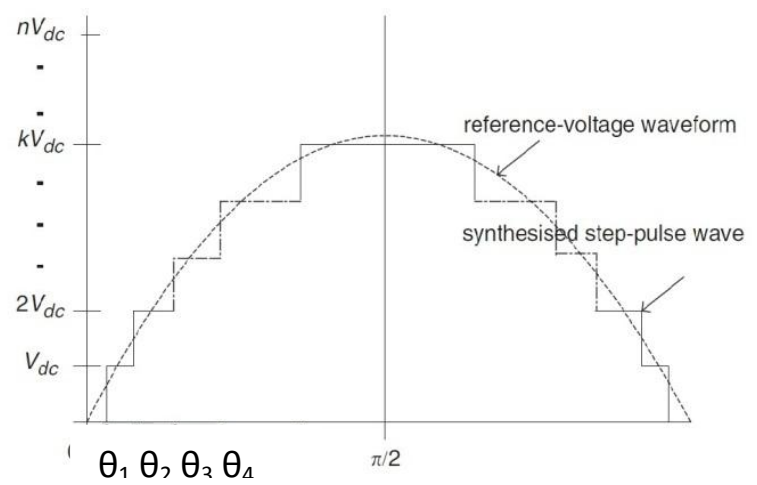

Fig. 2 Structure of cascaded multilevel Inverter

In this paper, a multilevel inverter based on the cascaded converter topology with 5 equal dc sources is studied. The key purpose of this paper is to commence a minimization technique assisted with Genetic Algorithm (GA) in order to decrease the computational burden associated with the solution of the nonlinear transcendental equations of the selective harmonic elimination method to reduce low order harmonics and to reduce THD.

\subsection{Selective harmonic elimination method}

The Selective Harmonic Eliminated PWM (SHE PWM) technique is used to find appropriate switching angles namely $\theta_{1}, \theta_{2}, \theta_{3}, \ldots, \theta_{N}$ so that the $(\mathrm{N}-1)$ odd harmonics can be eliminated and control of the fundamental voltage is also achieved. The Fourier series expansion for the quarter-wave symmetric staircase waveform as shown in Figure .1 is written as follows:

$\mathrm{V}_{\text {out }}(\omega \mathrm{t})=\sum_{n=1}^{\infty}\left[\left(\frac{4 V_{d c}}{n \pi}\right) \sum_{k=1}^{S} \cos \left(n \theta_{k}\right)\right] \sin n \omega t$

Where, $\theta_{\mathrm{k}}$ is the switching angles, which must satisfy the following condition: $\theta_{1}, \theta_{2}, \theta_{3}, \ldots \ldots \ldots, \theta_{\mathrm{s}}<\pi / 2$ and $\mathrm{s}$ is the number of H-bridge cells.

$\mathrm{n}$ is odd harmonic order And, V is the amplitude of dc voltage The harmonic components in the waveform can be describes as follows:

- the amplitude of dc component equals zero

- $\quad$ the amplitude of the fundamental component, $n=1$, and odd harmonic component are given by:

$$
\begin{aligned}
& \mathrm{h}_{1}=\left[\left(\frac{4 \mathrm{~V}_{\mathrm{dc}}}{\pi}\right) \sum_{\mathrm{k}=1}^{\mathrm{s}} \cos \left(\theta_{\mathrm{k}}\right)\right], \text { and } \\
& h_{n}=\left[\left(\frac{4 V_{d c}}{n \pi}\right) \sum_{k=1}^{s} \cos \left(n \theta_{k}\right)\right]
\end{aligned}
$$

- The amplitude of all even harmonics equals zero

Thus, only the odd harmonics in the quarter-wave symmetric multilevel waveform need to be eliminated. The switching angles of the waveform will be adjusted to get the lowest output voltage THD. The total harmonics distortion (THD) is mathematically given by:

$\mathrm{THD}=\sqrt{ } \Sigma \mathrm{h}_{\mathrm{n}}^{2} / \mathrm{h}_{1}$

In order control the fundamental amplitude and to eliminate the 5th, 7th, 11th, \& 13th lower order harmonics, the nonlinear transcendental equations set (4) must be solved and the five switching angles $\theta 1, \theta 2, \theta 3, \theta 4$ and $\theta 5$ are calculated offline to minimize the harmonics for each modulation index in order to have a total output voltage with a harmonic minimal distortion rate.

$\cos \left(\theta_{1}\right)+\cos \left(\theta_{2}\right)+\cos \left(\theta_{3}\right)+\cos \left(\theta_{4}\right)+\cos \left(\theta_{5}\right)=3 \pi \mathrm{M} / 4$

$\cos \left(5 \theta_{1}\right)+\cos \left(5 \theta_{2}\right)+\cos \left(5 \theta_{3}\right)+\cos \left(5 \theta_{4}\right)+\cos \left(5 \theta_{5}\right)=0$

$\cos \left(7 \theta_{1}\right)+\cos \left(7 \theta_{2}\right)+\cos \left(7 \theta_{3}\right)+\cos \left(7 \theta_{4}\right)+\cos \left(7 \theta_{5}\right)=0$

$\cos \left(11 \theta_{1}\right)+\cos \left(11 \theta_{2}\right)+\cos \left(11 \theta_{3}\right)+\cos \left(11 \theta_{4}\right)+$ $\cos \left(11 \theta_{5}\right)=0$

$\cos \left(13 \theta_{1}\right)+\cos 13\left(\theta_{2}\right)+\cos \left(13 \theta_{3}\right)+\cos \left(13 \theta_{4}\right)+$ $\cos \left(13 \theta_{5}\right)=0$

(4) the modulation index for the multilevel waveform is given as:

$\mathrm{M}=\frac{h_{1}}{s V}$ 
Where, $\mathrm{h} 1$ is the amplitude of the fundamental component. From equation, varying the modulation index value can control the amplitude of the fundamental component and the other s-1 nonlinear equations, which are the undesirable harmonic components, can be eliminated. These equations are solved by Newton-Raphson method [11]. In the natural sinusoidal PWM strategy, a large number of switching is required, with the consequent increase of switching losses. With the method of Selective Harmonic Elimination, only selected harmonics are eliminated with the smallest number of switching. This technique is very suitable for inverters control. By employing this technique, the low THD output waveform without any filter circuit is possible. Another approach uses genetic algorithm to optimize switching angle to reduce THD.

\section{GENETIC ALGORITHM}

Genetic algorithm is a computational model that solves optimization problems by imitating genetic processes and the theory of evolution by using genetic operators like reproduction, crossover, mutation etc. Amounts of applications have benefited from the utilization of genetic algorithm. Genetic algorithm is still a novel technique for PWM-SHE technique.

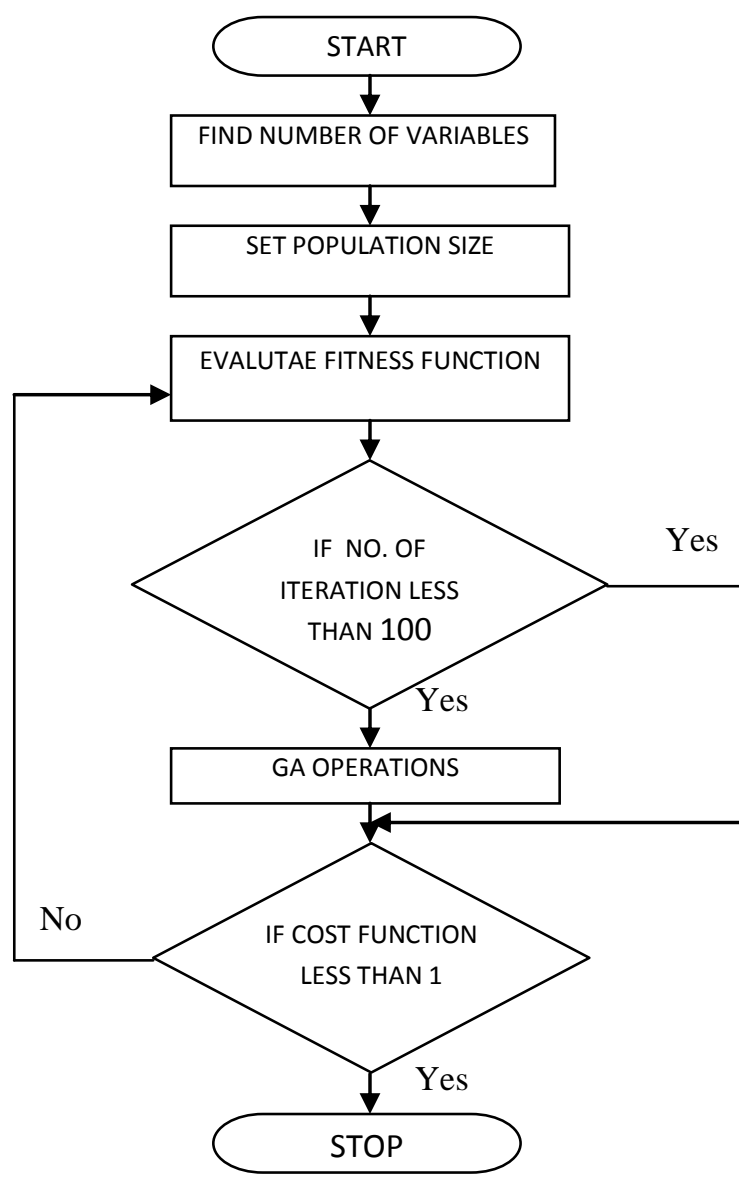

Fig. 3 Flowchart of Genetic Algorithm

This algorithm is usually used to accomplish a near global optimum solution. Each iteration of the GA is a new set of strings, which are called chromosomes, with improved fitness, is produced using genetic operators.

\subsection{Chromosome representation}

In GA, each chromosome is used as a feasible solution for the problem, where each chromosome is developed based on single dimensional arrays with a length of $\mathrm{S}$, where $\mathrm{S}$ is the number of angles.

\subsection{Initialize population}

Set a population size, $\mathrm{N}$, i.e. the number of chromosomes in a population. Then initialize the chromosome values randomly. If known, the range of the genes should be considered for initialization. Population size depends only on the nature of the problem and it must achieve a balance between the time complexity and the search space measure. The narrower the range, the faster GA converges. In this paper, population size is considered as 100

\subsection{Reproduction}

The reproduction operator determines how the parents are chosen to create the offspring. This operator is a process in which chromosomes are copied according to their objective function values i.e. the degree of conformity of each object is calculated and an individual is reformed under a flat rule depending on the degree of conformity.

\subsection{Crossover}

Crossover is the most significant operation in GA. It creates a group of children from the parents by exchanging genes among them. The new offspring contain mixed genes from both parents. By doing this, the crossover operator not only provides new points for further testing within the chromosomes, which are already represented in the population, but also introduces representation of new chromosomes into the population to allow further evaluation on parameter optimization.

\subsection{Mutation}

Mutation is another vital operation. It works after crossover operation. In this operation, there is a probability that each gene may become mutated when the genes are being copied from the parents to the offspring. This process is repeated, until the preferred optimum of the objective function is reached.

\subsection{Evaluation of fitness function}

The most vital item for the GA to evaluate the fitness of each chromosome is the cost function. The purpose of this study is to minimize specified harmonics; therefore the fitness function has to be associated to THD. In this work the fifth, seventh, eleventh, and thirteenth harmonics at the output of an eleven-level inverter are to be minimized.

$\mathrm{FV}=\frac{\sqrt{\sum_{n=5,7,11,13}\left(\frac{1}{n} \sum_{k=1}^{5} \cos \left(n \alpha_{k}\right)\right)^{2}}}{\sum_{k=1}^{5} \cos \alpha_{k}}$

For each chromosome a multilevel output voltage waveform is produced using the switching angles in the chromosome and the required harmonic magnitudes are calculated using FFT techniques.

GA is typically set to run for a certain number of iterations (100 in this case) to get an answer. After the first iteration, FV's are used to determine new offspring. These go through crossover and mutation operations and a new population is created which goes through the same cycle starting from FV evaluation. Sometimes, GA can converge to a solution much before 100 iterations are completed. To save time, in this paper, the iterations have been stopped when the cost function goes below 1 .

\section{SIMULATION RESULTS}

From the simulation results using genetic algorithm, it is clear that for 11-Level cascaded multilevel inverter the 5th, 7th, 11th and 13th harmonics and for 7-Level inverter 5th, 7th harmonics and their magnitudes are negligible relatively to the fundamental component. The obtained switching angles for various values of modulation index using GA for 11-level inverter and 7-Level 
inverter is shown in Table 1 and Table 2 respectively. Fig.4 shows the simulation results for the output voltage waveform of 11-level inverter for $M=0.8$. Fig.5, Fig.6 and Fig.7 shows the FFT spectrum of THD of an 11- level multilevel inverter, Optimal switching angles for various values of $\mathrm{M}$ and THD of 11-level multilevel inverter. Fig.8 shows the simulation results for the output voltage waveform of 7-level inverter for $\mathrm{M}=0.9$, Fig.9 shows Optimal switching angles for various value of $M$. Table. 3 shows THD for 7-level and 11- level inverter.

Table.1 Switching angles generated by GA for 11-level

\begin{tabular}{|c|c|c|c|c|c|}
\hline \multirow{2}{*}{$\begin{array}{l}\text { Modulation } \\
\text { Index (M) }\end{array}$} & \multicolumn{5}{|c|}{ Switching Angles } \\
\hline & $\begin{array}{l}\theta_{1} \\
\text { (rad.) }\end{array}$ & $\begin{array}{l}\theta_{2} \\
(\mathrm{rad} .)\end{array}$ & $\begin{array}{l}\theta_{3} \\
(\mathrm{rad} .)\end{array}$ & $\begin{array}{l}\theta_{4} \\
\text { (rad.) }\end{array}$ & $\begin{array}{l}\theta_{5} \\
(\mathrm{rad} .)\end{array}$ \\
\hline 0.1 & 0.215 & 0.373 & 0.621 & 0.973 & 1.083 \\
\hline 0.2 & 0.212 & 0.356 & 0.602 & 0.952 & 1.086 \\
\hline 0.3 & 0.225 & 0.358 & 0.61 & 0.978 & 1.074 \\
\hline 0.4 & 0.19 & 0.524 & 0.723 & 1.108 & 1.503 \\
\hline 0.5 & 0.348 & 0.633 & 0.907 & 1.013 & 1.218 \\
\hline 0.6 & 0.475 & 0.777 & 0.896 & 1.099 & 1.27 \\
\hline 0.7 & 0.041 & 0.236 & 0.592 & 0.724 & 1.467 \\
\hline 0.8 & 0.098 & 0.299 & 0.514 & 0.760 & 1.087 \\
\hline 0.9 & 0.154 & 0.419 & 0.721 & 1.063 & 1.543 \\
\hline 1.0 & 0.324 & 0.655 & 0.968 & 1.119 & 1.538 \\
\hline
\end{tabular}

Table.2 Switching angles generated by GA for 7-level

\begin{tabular}{|l|l|l|l|}
\hline \multirow{2}{*}{$\begin{array}{l}\text { Modulation } \\
\text { Index }\end{array}$} & \multicolumn{3}{|l|}{ Switching Angles } \\
\cline { 2 - 4 } & $\theta_{1}$ (rad.) & $\theta_{2}$ (rad.) & $\theta_{3}$ (rad.) \\
\hline 0.1 & 0.215 & 0.373 & 0.621 \\
\hline 0.2 & 0.212 & 0.356 & 0.602 \\
\hline 0.3 & 0.225 & 0.358 & 0.61 \\
\hline 0.4 & 0.19 & 0.524 & 0.723 \\
\hline 0.5 & 0.348 & 0.633 & 0.907 \\
\hline 0.6 & 0.475 & 0.777 & 0.896 \\
\hline 0.7 & 0.041 & 0.236 & 0.592 \\
\hline 0.8 & 0.098 & 0.299 & 0.514 \\
\hline 0.9 & 0.154 & 0.419 & 0.721 \\
\hline 1.0 & 0.324 & 0.655 & 0.968 \\
\hline
\end{tabular}

Table.3 THD for 7-level and 11-level inverter

\begin{tabular}{|l|l|}
\hline Level & THD $(\%)$ \\
\hline Seven & 17.29 \\
\hline eleven & 8.04 \\
\hline
\end{tabular}

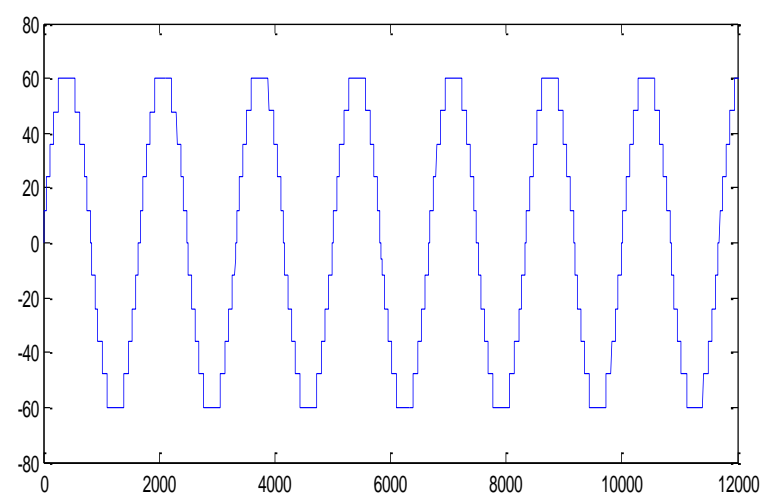

Fig. 4 Output Voltage of 11-Level Inverter

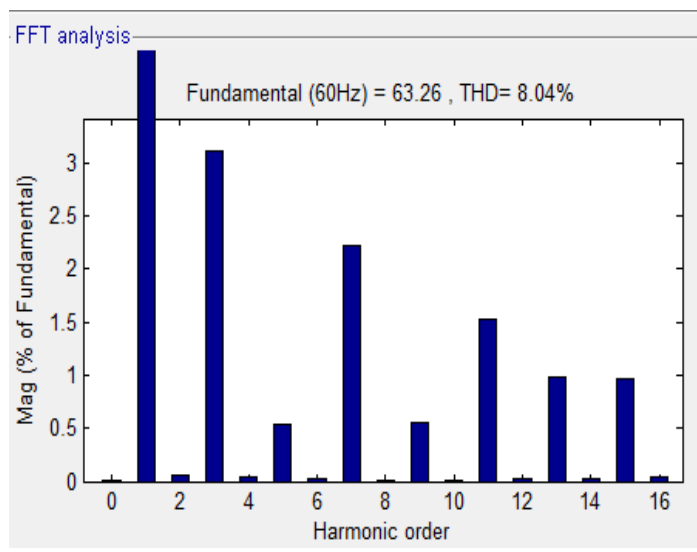

Fig. 5 FFT analysis of 11-Level Multilevel inverter

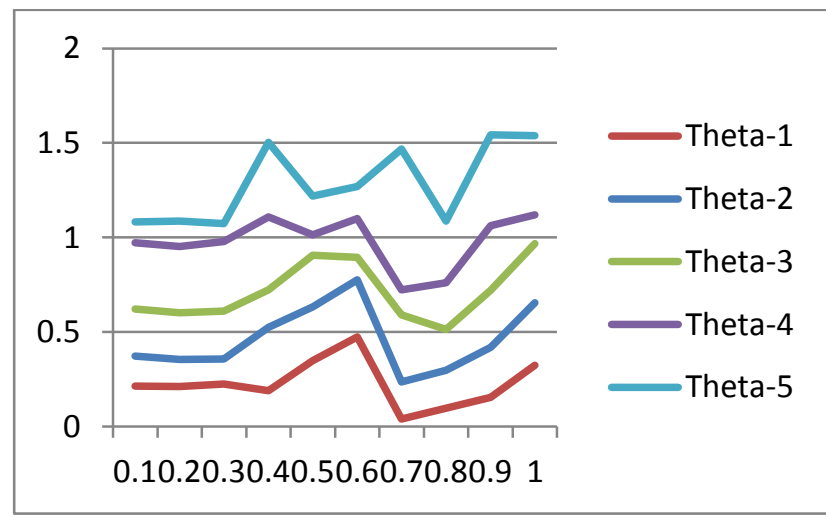

Fig. 6 Optimal switching angles Vs M. 


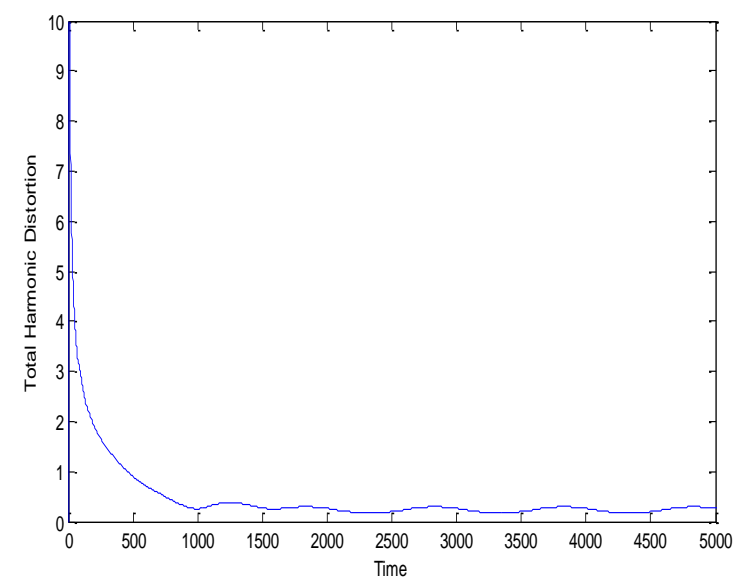

Fig.7 THD of an 11- level multilevel inverter

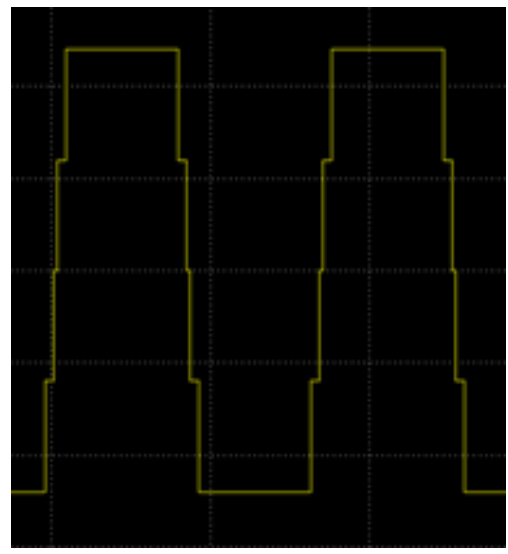

Fig. 8 Output Voltage of 7-Level Inverter

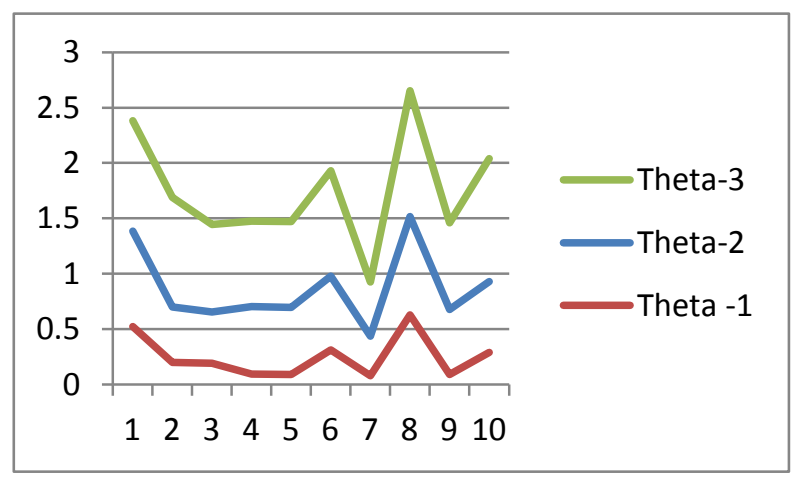

Fig.9 Optimal switching angles Vs M.

\section{CONCLUSION}

In this work, genetic algorithm optimization technique is applied to find the switching angles of the cascaded inverter for the reduction of harmonics. The use of the GA is proposed to solve the selective harmonics elimination problem in PWM inverters. The paper successfully demonstrates the validity of genetic algorithm for the estimation of optimum switching angles of staircase waveform generated by multilevel inverters, and Comparison has been done between the 7-level and 11-level with respect to the consideration of THD. As number of level increases THD decreases; therefore THD of 7-level inverter is greater than THD of 11-level.As in this approach, GA can be applied to any problem where optimization is required; therefore, it can be used in many applications in power electronics.

\section{REFERENCES}

[1] P.M. Bhagwat and V.R. Stefanovic, "Generalized structure of a multilevel PWM inverter", IEEE Trans. On I.A., Vol. IA19, n. 6. 1983, pp. 1057-1069.

[2] J. Lai and F.Z. Peng, "Multilevel converters - A new breed of power converters", IEEE IAS Annual Conference Records, 1995, pp. 2348-2356.

[3] F.Z. Peng, J. Lai, J. McKeever and J. VanCOevering, "A multilevel voltage-source inverter with separate dc sources for static var generation", IEEE IAS Annual Conference Records, 1995, pp. 2541-2548.

[4] H. L. Liu and G.H. Cho, "Three-level space PWM in low index modulation region avoiding narrow pulse problem", IEEE IAS Annual Conference Records, 1993, pp. 257-262.

[5] Rodriguez J, Bernet S, Wu B, Pontt J.O, Kouro S. "Multilevel voltage-source-converter topologies for industrial mediumvoltage drives". IEEE Trans. Ind. Electron. Vol. 54, Dec. $2007,2930-2945$

[6] A. Nabae, I. Takahashi, H. Agaki "A New Neutral-PointClamped PWM, Inverter," IEEE Transactions on Industry Applicaitions. Vol.IA-17, No.5, Sep./Oct 1981, pp.518-523.

[7] B. Wu, P. G Song, "Comprehensive Analysis of MultiMegawatt Variable Frequency Drives", Transaction of China Electrotechnical Society, Vol.19, No.8, pp. 40-52, 2004

[8] L. M. Tolbert, F. Z. Peng, and T. G. Habetler, "Multilevel converters for large electric drives," IEEE Trans. Ind Applicat., Vol. 35, pp. 36-44, Jan./Feb.1999.

[9] P.W. Hammond, "A New Approach to Enhance Power Quality for Medium Voltage AC Drives,' IEEE Trans. on Industry Applications," Vol.33, No.1, pp202-208,1997.

[10] W A Hill, and C D Harbourt, Performance of Medium Voltage Multi-level Inverter, IEEE Industry Application Society Annual Meeting (IAS), pp.1186-1192, 1999.

[11] Sirisukprasert, Siriroj. (1999) "Optimized Harmonic Stepped-Waveform for Multilevel Inverter", Msc thesis, available at http://www.worldcatlibraries.org

[12] F. Z. Peng, J. S. Lai, J. McKeever and J.VanCoevering, "A Multilevel Voltage-Source Inverter with Separate DC Sources for Static Var Generation," IEEE-IAS Con\$ Rec., pp2541 -2548.

[13] G. Joos, X. Huang and B. T. Ooi, "Direct-coupled Multilevel Cascaded Series VAR Compensators," IEEEIAS Con\$. Rec., pp. 1608-1615, 1997.

[14] F. Huang, P. I. Lim and E. K. Goh, "Design and Implementation of a 3- Phase Voltage Stabilizer Using 1 1Level Voltage Source Inverter," IEEEIECON Con\$ Rec., pp. 722-725, 1997

[15] Lai Y S, Shyu F S. (2002) "Topology for hybrid multilevel inverter," IEE Proceedings-Electric Power Applications, , vol.149, pp.449-458.

[16] P.P. Bhagwat, and V. R. (1983) "Generalized structure of a multilevel PWM inverter," IEEE Transactions in Industry Applications, vol.19, pp.1057-1069.

[17] J. Sun, S. Beineke, and H. Grotstollen, "Optimal PWM based on realtime solution of harmonic elimination 
equations," IEEE Trans. Power Electron., vol. 11, no. 4, pp. 612-621, Jul. 1996.

[18] J. R. Wells, X. Geng, P. L. Chapman, P. T. Krein, and B. M. Nee, "Modulation-based harmonic elimination," IEEE Trans. Power Electron., vol. 22, no. 1, pp. 336-340, Jan. 2007.

[19] J. Wang, Y. Huang, and F. Z. Peng, "A practical harmonics elimination method for multilevel inverters," in Conf. Rec. IEEE IAS Annu. Meeting, Oct. 2005, vol. 3, pp. 16651670.
[20] L. Chambers.( 1995) "Practical handbook of genetic algorithms" Boca Raton, CRC Press.

[21] S.N.Sivanandam, \& S.N.Deepa (2011). Principles of Soft Computing, Second edition page(s):385-401

[22] Goldberg D.E. (1989). Genetic Algorithm in Search, Optimization and Machine Learning, MA: Addison Wesley

[23] Davis.L. (1991). Handbook of Genetic Algorithm, New York: Van Nostran 